\title{
Pathological Workup of Surgical Breast Cancer Specimens after Neoadjuvant Chemotherapy
}

\author{
Carsten Denkert \\ Institut für Pathologie, Charité Universitätsmedizin Berlin, Campus Mitte, Germany
}

\author{
Key Words \\ Breast cancer · Neoadjuvant · Pathology · Pathological \\ complete remission
}

\begin{abstract}
Summary
In neoadjuvant therapy studies of patients with breast cancer, the histopathological evaluation of tumor regression, in particular the identification of those patients with a pathological complete remission ( $\mathrm{pCR}$ ) of all tumor cells after neoadjuvant therapy is of central importance. Many parameters of the histological diagnosis are similar or identical in tumor specimens from neoadjuvant approaches and from standard surgical procedures. However, there are some situations in the context of neoadjuvant therapy that are different from these standard approaches. For adequate diagnosis of changes associated with neoadjuvant therapy, an efficient communication between clinicians and pathologists is essential. In this review, the standard elements are reviewed briefly and an additional focus is put on the special situations in the histological diagnosis in neoadjuvant studies, such as regression grading, evaluation for complete pathological response (pCR) and pseudo-multifocality. Furthermore, we will discuss new opportunities for tissue-based translational research for biomarker evaluation and concepts of research.
\end{abstract}

\section{Introduction}

Neoadjuvant chemotherapy concepts have been developed in the last years and provide a valid option for many patients with primary breast cancer [1]. Aims of the neoadjuvant therapy [2] are: i) elimination of all tumor cells by a combination

\author{
Schlüsselwörter \\ Mammakarzinom · Neoadjuvant · Pathologie · \\ Pathologische Komplettremission
}

\section{Zusammenfassung}

In neoadjuvanten klinischen Studien zur Therapie des Mammakarzinoms werden wichtige Endpunkte durch die histopathologische Diagnostik generiert. Insbesondere die Beurteilung der Tumorregression ist klinisch von Bedeutung, da gezeigt werden konnte, dass diejenigen Patientinnen mit einer pathologisch gesicherten Komplettremission ( $p C R$ ) eine besonders günstige Prognose haben. Für die standardisierte Aufarbeitung ist eine effiziente Kommunikation zwischen dem Kliniker und dem Pathologen unerlässlich. Die Richtlinien zur histologischen Diagnostik für neoadjuvante Therapien und Standardsituationen sind in vielerlei Hinsicht ähnlich. In diesem Review werden die allgemeinen Richtlinien nur kurz dargestellt, der Schwerpunkt liegt auf besonderen Situationen in der neoadjuvante Therapie. Dazu gehören das Regressions-Grading, die Evaluation der pathologischen Komplettremission (pCR) und das Problem der therapieinduzierten Pseudo-Multifokalität. Die neoadjuvanten Therapiekonzepte bieten zudem vielfältige Möglichkeiten für translationale Forschungsprojekte zur BiomarkerValidierung.

of chemotherapy and surgical treatment, ii) improvement of the surgical treatment options, in particular in large advanced tumors, and iii) generation of data on the response of the tumor to chemotherapy. This response information may be used to modify the therapy of the individual patient [3] and to improve therapeutic concepts.

\begin{tabular}{|c|c|}
\hline KARGER & (c) 2006 S. Karger GmbH, Freiburg \\
\hline $\begin{array}{l}\text { Fax +4976145207 14 } \\
\text { E-mail Information@Karger.de } \\
\text { www.karger.com }\end{array}$ & $\begin{array}{l}\text { Accessible online at: } \\
\text { www.karger.com/brc }\end{array}$ \\
\hline
\end{tabular}

PD Dr. Carsten Denkert 
In neoadjuvant studies, the pathological diagnosis is the most important parameter for the generation of study endpoints [4]. The histopathological evaluation of tumor regression, in particular the identification of those patients with a complete regression of all tumor cells after neoadjuvant therapy, is of central importance [5, 6].

It should be emphasized that most elements of the histological diagnosis are similar or identical in tumor specimens from neoadjuvant situations and from standard surgical procedures. The histopathological evaluation should be performed according to the current diagnostic standards of breast pathology that have been described in the national S3 Guideline of the German Cancer Society or similar international guidelines [7-9]. However, there are some situations in the context of neoadjuvant therapy that are different from these standard approaches. In this review, we will briefly discuss the standard elements and then put an additional focus on the special challenges for histological diagnosis in neoadjuvant studies. Furthermore, the new opportunities for tissue-based translational research for biomarker evaluation and concepts of research will be discussed.

Throughout the development of neoadjuvant study concepts, various definitions of pathological complete remission (pCR) have been used. Today, the most accepted definition is the regression of all invasive and in-situ tumor components in the primary tumor as well as in the lymph nodes. For histological description of those cases that do not fulfill the criteria of complete regression, systems for regression grading have been developed. In Germany, the system developed by Sinn et al. [10] is used in most cases. However, international studies often use different grading systems. This review will therefore focus on the minimum information in histopathological description of regression in neoadjuvant chemotherapy to ensure the compatibility of national and international regression grading systems.

\section{Communication in Neoadjuvant Studies}

In the diagnosis and treatment of patients with breast cancer, there have been extensive approaches towards standardization and the establishment of multi-disciplinary networks. In all breast cancer centers, interdisciplinary tumor conferences are organized on a weekly basis. These networks are particularly useful for the communication between gynecologic oncologists, radiologists and pathologists for the diagnostic workup of patients in neoadjuvant breast cancer studies.

Standardized diagnostic and histopathological workup of specimen from neoadjuvant trials is an essential element of these studies, since pCR is the most important outcome parameter of these studies [11].

For adequate diagnosis of changes associated with neoadjuvant therapy, an efficient communication between clinicians and pathologists is essential. Table 1 gives an overview on the minimum of 4 essential clinical parameters that should be reported to the pathologist together with tumor specimen from clinical neoadjuvant trials. The most important information is the information that a neoadjuvant therapy has been given. In the experience of many pathologists, this information is not given by the clinicians in many cases. The lack of this information is one of the major reasons for inadequate histological workup in neoadjuvant therapy. As only a minority of breast cancer patients is treated by neoadjuvant therapy, the pathologist may not recognize these patients solely based on the histological changes. In those cases where there is only a poor response to neoadjuvant therapy, the histological changes may be very uncharacteristic. Further essential information includes data on the clinical response, the pretherapeutic size of the tumor as well as the localization of the tumor, which is needed for macroscopic evaluation and the sampling of tissue for histological diagnosis. The pathological approach for the sampling of tissue will be completely different if the pathologist has the additional information that the pretherapeutic tumor is a very large one, because additional samples from the tumor bed as well as from the margins will be taken.

Neoadjuvant chemotherapy may be associated with an increased rate of local recurrences. As the residual tumor after therapy is often growing in small discontinuously infiltrating nests, clinical information on the size and location of the pretherapeutic tumor bed is needed to guide histopathological assessment of margin status and may therefore contribute to the reduction of tumor recurrences.

\section{Standardized Histopathological Diagnosis of Pretherapeutic Punch Biopsies}

Today, the diagnosis of breast cancer is usually made by pretherapeutic punch biopsies. These biopsies consist of 1-5 tissue biopsy cylinders from the tumor that are usually fixed in buffered formalin for histopathological diagnosis.

In the classical diagnostic approach, these biopsies have been used primarily for diagnosis of malignancy as a basis for therapeutic excision of the breast tumor. In these cases, the subtyping, grading as well as hormone receptor and HER-2 staining used to be performed using the resection specimen that provides an increased amount of tissue. However, due to changes in the pretherapeutic workup of breast cancer patients, the histopathological evaluation of punch biopsies has already been adjusted in many centers. Very often, the clinical decisions for therapy are made prior to surgery, based solely on the punch biopsies. The increased spectrum of therapeutic approaches requires the generation of all information that is necessary for diagnosis and therapy planning. For example, in many breast centers, patients with invasive lobular carcinoma may receive extended presurgical imaging including magnetic resonance imaging (MRI) studies to guide surgery in these ir- 
Table 1. 4 essential parameters that should be given to the pathologist for each tumor resection specimen from neoadjuvant therapy

\begin{tabular}{ll}
\hline Clinical information & Why is this information important for the pathologist? \\
\hline $\begin{array}{l}\text { 1. Neoadjuvant therapy has been performed } \\
\text { The histopathological approach is completely different in neoadjuvant situations: A different } \\
\text { tumor classification (ypTNM) has to be used after neoadjuvant therapy. Regression grading has } \\
\text { to be performed. Histological changes in poor responders may be very uncharacteristic and may } \\
\text { not be recognized without clinical information. }\end{array}$ \\
$\begin{array}{ll}\text { Histopathological evaluation for complete pathological response will focus on the size of the } \\
\text { pretherapeutic tumor bed. This size cannot be reliably determined from the resection specimen } \\
\text { T. Pretherapeutic tumor size }\end{array}$ & $\begin{array}{l}\text { To reduce local recurrences after neoadjuvant therapy, adequate sampling of margins is } \\
\text { necessary. Since residual tumor may be discontinuously located close to the margins, an exact } \\
\text { clinical description of the localization is needed. }\end{array}$ \\
$\begin{array}{l}\text { location of residual tumor foci in clinical and } \\
\text { imaging approaches }\end{array}$ & $\begin{array}{l}\text { In the setting of clinical complete response, the macroscopic evaluation and the sampling are } \\
\text { different. Histological workup time will be much shorter if this information is given when } \\
\text { sending the specimen. }\end{array}$ \\
\hline
\end{tabular}

Table 2. Standardized histological diagnosis of pretherapeutic punch biopsies in neoadjuvant therapy

\begin{tabular}{ll}
\hline Histopathological parameter & Why is this parameter important for the clinician in the setting of neoadjuvant therapy? \\
\hline Tumor type & $\begin{array}{l}\text { Surgery and additional imaging studies are different in some tumor subtypes, particularly in invasive lobular } \\
\text { carcinoma. }\end{array}$ \\
Grading & $\begin{array}{l}\text { Well differentiated tumors have a reduced response rate to chemotherapy [21]. } \\
\text { Hormone receptor status }\end{array}$ \\
Her-2 status & $\begin{array}{l}\text { Hormone receptor-positive tumors have a reduced response rate to chemotherapy. } \\
\text { therapy concepts seem to have a particularly high rate of complete remissions [15]. }\end{array}$ \\
\hline
\end{tabular}

regularly infiltrating tumors. Since the classical histological characteristics of lobular carcinoma may be difficult to evaluate in core biopsies where only few tumor cells are present, establishment of the diagnosis may require immunohistochemical evaluation of the adhesion molecule E-cadherin which is constantly lost in lobular carcinoma and contributes to the diffuse infiltrative growth pattern observed in these tumors.

Table 2 gives an overview of the elements of the histological diagnosis of breast cancer punch biopsies. This information includes the histological type, the histological grade, hormone receptor status as well as HER-2 status. The tumor type should be determined according to the WHO classification [12], the histological grade according to Elston and Ellis with an adjustment of the mitotic rate to the individual parameters of each microscope [13]. The hormone receptor (estrogen receptor and progesterone receptor) status should be given as percentage of positive cells. In addition, the intensity of the staining and the immunoreactive score according to Remmele and Stegner [14] should be reported. For Her-2, the Hercept score should be used, and HER-2 2+ cases should be evaluated by additional FISH analysis.

It is essential that in the setting of neoadjuvant chemotherapy the complete morphological information is reported in the punch biopsy specimen, since there may be no additional tumor left in the case of a pCR. Furthermore, modern neoadjuvant concepts include the use of trastuzumab and will include other molecular targeted drugs in the future. The first results from neoadjuvant studies using Her-2 suggest that a pCR can be reached in a comparable high subset of cases [15]. As this therapeutic approach offers excellent opportunities for the patient, it is essential that molecular predictive markers like HER-2 are addressed in the punch biopsies at least in the setting of a planned neoadjuvant therapy.

It should be noted that pathological tumor characteristics and marker expression may vary between different areas of the tumor. This may result in differences between the punch biopsy and the resection specimen in a subset of cases. Furthermore, differences in grading and tumor type may occur. It should be communicated to the clinical partners that these differences reflect tumor heterogeneity and cannot be completely avoided. However, as a result of technical advances in many cases, several punch biopsies from different areas of the tumor are sent for histological diagnosis, which reduces problems caused by tumor heterogeneity. Furthermore, in the resection specimen, an inflammatory reaction induced by the previous punch biopsy is observed, which may also lead to differences in biomarker expression. 


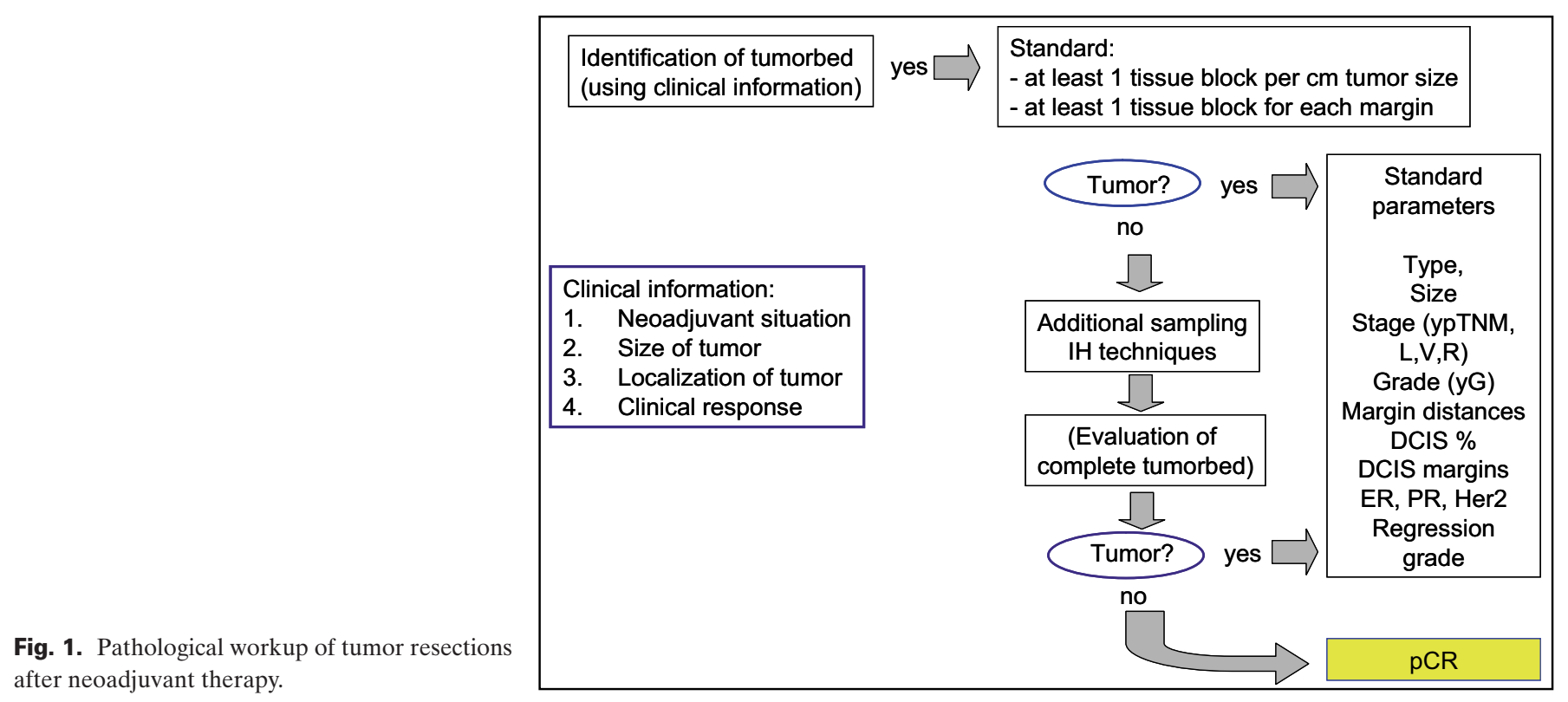

\section{Standardized Histopathological Diagnosis of Tumor Resections after Neoadjuvant Chemotherapy}

After the neoadjuvant chemotherapy, tumor resection is performed as a local resection or a mastectomy depending on the clinical situation. As the general histopathological parameters are similar between conventional surgical therapy and neoadjuvant therapy, the focus of this review will be on the special situations in neoadjuvant therapy. A general overview of the pathological workup of resection specimen after neoadjuvant therapy is given in figure 1 .

The standardized histopathological report after neoadjuvant therapy should include the following. i) The histopathological tumor classification according to WHO [9]. ii) The histological grading according to Elston and Ellis [13] with the addition 'status post-chemotherapy,' or classification as 'yG'. This addition reflects the fact that changes induced by chemotherapeutic agents change the histological characteristics of the tumor cells by eliminating the proliferating cells and by inducing changes in nuclear size and nuclear conformation in the remaining cells. This will result in a reduced mitotic count and an increased nuclear grade in many cases and might therefore lead to a different grade compared to the presurgical biopsy. The grading should be performed to allow comparison of pretherapeutic and posttherapeutic grading. iii) The tumor size with additional information on the presence of multifocal of multicentric tumor nests. iv) Intraductal tumor component: type, percentage, localization, size and grading according to WHO. v) The margin status with the distance of the tumor to all six margins, if necessary different distances for the invasive and the intraductal component should be reported. vi) The hormone receptor status: percentage, intensity and immunoreactive score. vii) The HER-2 status (Her-2 score). viii) The regression grade (see below) [10]. ix) Lymphatic invasion or venous invasion. $\mathrm{x}$ ) Nodal status: the report should include the number of nodes with residual tumor as well as those nodes that contain areas of sclerosis that can indicate tumor regression induced by chemotherapy. xi) ypTNM classification [12]

\section{Regression Grading}

In the development of neoadjuvant therapy concepts in national and international studies, several regression grading systems have been developed and are currently in use [10, 16-18]. However, most of these grading systems have not been systematically evaluated in prospective clinical studies for their predictive power. While it has been shown that $\mathrm{pCR}$ is predictive for survival, the further elements of the regression grading have not been validated to a great extent. An overview on different grading systems is given in [19] and [2]. To give a basis for the future international standardization of regression grading and to allow the comparison of different studies, a two-step approach has been suggested. In the first step, a standardized minimum number of pathological parameters should be reported in each pathological report (table 3 A). These parameters allow the comparison of different studies and would allow the translation of the results from one grading system into another for combined analysis and comparison. In the second step, a regression grading should be reported using one of the established grading systems. In Germany, this will be the regression grading reported by Sinn et al. $[10,20]$ which is widely accepted, but in other countries other systems might be used. The regression grading by Sinn et al. [10] is shown in table $3 \mathrm{~B}$. 
Table 3. Parameters essential for reporting of regression grading (A) and regression grading scoring system according to Sinn et al. [10] (B)

\begin{tabular}{|c|c|}
\hline \multicolumn{2}{|c|}{ A. Essential parameters for pathological report of regression grading } \\
\hline Presence of sclerosis & descriptive (strong/moderate/minimal) \\
\hline Presence of resorptive inflammation & descriptive (strong/moderate/minimal) \\
\hline Cytopathic effects & in the majority of cells / in a minority of cells / only in single cells \\
\hline Size of invasive residual tumor & total size $(=\mathrm{ypT}) ;$ multifocal tumor: largest focus of tumor cells $(<5 \mathrm{~mm}$ or $\geq 5 \mathrm{~mm})$ \\
\hline Presence of ductal carcinoma in situ (DCIS) & percentage compared to the area of the invasive tumor; size and localization of DCIS \\
\hline Changes in lymph nodes & $\begin{array}{l}\text { number of nodes with residual tumor; number of nodes with partial sclerosis but without residual } \\
\text { tumor; total number of nodes }\end{array}$ \\
\hline \multicolumn{2}{|l|}{ B. Regression grading according to Sinn et al. [10] } \\
\hline Regression grade 0 & no effect \\
\hline Regression grade 1 & sclerosis, resorptive inflammation and/or cytopathic effects in the tumor cells \\
\hline Regression grade 2 & $\begin{array}{l}\text { extensive tumor sclerosis with only focal or multifocal minimal-invasive residual tumor (largest } \\
\text { focus }<5 \mathrm{~mm} \text { ) }\end{array}$ \\
\hline Regression grade 3 & no invasive residual tumor, residual in-situ tumor only \\
\hline Regression grade 4 & no invasive or in-situ residual tumor ( = pathological complete remission) \\
\hline
\end{tabular}

\section{Special Situations in the Macroscopic and Microscopic Evaluation of Tumor Specimens after Neoadjuvant Therapy}

\section{Macroscopically Well-Defined Tumor}

In cases where the tumor is easily visible on gross examination of the specimen, there will be usually no problems with the histopathological evaluation, since the macroscopic and microscopic evaluation is similar to the standard situation without neoadjuvant therapy. At least 3 blocks of tumor tissue as well as the distance to all margins should be evaluated. Furthermore, fibrous areas in the vicinity of the tumor should be evaluated.

\section{Irregularly Defined or Poorly Visible Tumor Bed}

In cases where the tumor is not clearly visible on gross examination, tissue from the tumor bed should be examined to document the response to the neoadjuvant therapy (fig. 1). This is only possible if clinical information on the size and location of the tumor bed is available. In this area, the tumor bed is usually visible as an irregular area of fibrosis. The extend of examination should be adjusted to the pretherapeutic size of the tumor. At least one tissue block for each centimeter of tumor should be investigated.

\section{Regression Grade 3 or 4}

In those cases where a regression grade 3 (in-situ only) or 4 (no residual tumor) is suspected, additional tissue from the tumor bed and the surrounding fibrous areas should be investigated. Since there may be only very small residual foci of tumor cells with a size of only a few millimeters after therapy, the complete tumor bed may be investigated (fig. 1). In some cases, the distinction between regressive tumor cells and activated histiocytes may be difficult. In those cases, additional immunohistochemical investigations using epithelial and histiocytic markers are helpful.

\section{Determination of the Tumor Size after Therapy}

After neoadjuvant chemotherapy, a so-called therapy-induced pseudo-multifocality may be observed. In those cases, the determination of the tumor size after neoadjuvant therapy should be based on the combination of gross examination and microscopic investigation. If there are several separate tumor cell nests in a macroscopically defined fibrous tumor bed, the macroscopic tumor size should be used for the ypT classification. In addition, the size of the largest single nest of tumor cells should be reported. A multifocal tumor should only be diagnosed in those situations where there are separate tumor cell nests that are not located in one macroscopically determined fibrous area which is corresponding to the pretherapeutic tumor bed.

\section{Determination of the Margin Status after Neoadjuvant Chemotherapy}

Several studies have reported a slightly increased rate of local tumor recurrences after neoadjuvant therapy. To reduce these recurrences, a careful examination of the resection margins is necessary, particularly in those cases where there is increased fibrosis and discontinuous tumor cell nests.

\section{Evaluation of Lymphatic Nodes}

For the evaluation of lymph nodes, a separate regression grading should be performed. If fibrous areas within the nodes are observed, the number of those nodes with fibrous areas should be reported. In addition, immunohistochemical investigations may be considered to rule out small regressive residual tumor cell nests. 


\section{Concepts for Translational Research}

While this review is focused on the standardized histopathological workup of tumor tissue from neoadjuvant studies, it should be emphasized that these study concepts offer additional opportunities for translational research. The advantage of neoadjuvant studies is that the response to chemotherapy can be determined immediately after surgery. Therefore, the investigation of biomarkers on the mRNA and protein level in presurgical punch biopsies as well as in tumor tissue from the surgical resection can be correlated with the response data. In the neoadjuvant clinical trials, translational research companion protocols are developed to investigate biomarkers for prediction of therapy response. Since the molecular biological techniques for investigations of markers on the protein and mRNA level have made a lot of progress during the last decade, even very small biopsy specimens from presurgical punch biopsies can be used to measure several protein markers and mRNA markers in parallel. For analysis of protein markers, tissue-multi arrays (TMA) are used to allow simultaneous processing of hundreds of samples. For analysis of mRNA markers, protocols have been developed for isolation of mRNA from formalin-fixed paraffin-embedded tissue. In the future, new therapy concepts using molecular targeted drugs will require the development of valid predictive biomarkers. In this setting, tumor biobanks that are generated from the tissue samples of neoadjuvant studies are particularly useful.

\section{References}

1 Kaufmann M, von Minckwitz G, Smith R, Valero V, Gianni L, Eiermann W, Howell A, Costa SD, Beuzeboc P, Untch M, Blohmer JU, Sinn HP, Sittek R, Souchon R, Tulusan AH, Volm T, Senn HJ: International expert panel on the use of primary (preoperative) systemic treatment of operable breast cancer: review and recommendations. J Clin Oncol 2003;21:2600-8, review.

2 Kaufmann M, Hortobagyi GN, Goldhirsch A, Scholl S, Makris A, Valagussa P, Blohmer JU, Eiermann W, Jackesz R, Jonat W, Lebeau A, Loibl S, Miller W, Seeber S, Semiglazov V, Smith R, Souchon R, Stearns V, Untch M, von Minckwitz G: Recommendations from an international expert panel on the use of neoadjuvant (primary) systemic treatment of operable breast cancer: an update. J Clin Oncol 2006;24:1940-9.

-3 Von Minckwitz G, Blohmer JU, Raab G, Lohr A, Gerber B, Heinrich G, Eidtmann H, Kaufmann M, Hilfrich J, Jackisch C, Zuna I, Costa SD; German Breast Group: In vivo chemosensitivity-adapted preoperative chemotherapy in patients with earlystage breast cancer: the GEPARTRIO pilot study. Ann Oncol 2005;16:56-63.

$\checkmark 4$ Chollet P, Amat S, Cure H, de Latour M, Le Bouedec G, Mouret-Reynier MA, Ferriere JP, Achard JL, Dauplat J, Penault-Llorca F: Prognostic significance of a complete pathological response after induction chemotherapy in operable breast cancer. Br J Cancer 2002;86:1041-6.

$\checkmark 5$ Amat S, Abrial C, Penault-Llorca F, Delva R, Bougnoux P, Leduc B, Mouret-Reynier MA, MeryMignard D, Bleuse JP, Dauplat J, Cure H, Chollet P: High prognostic significance of residual disease after neoadjuvant chemotherapy: a retrospective study in 710 patients with operable breast cancer. Breast Cancer Res Treat 2005;94:255-63.

6 Anderson BO: Pathologic response to preoperative systemic therapy: the new biological paradigm for predicting outcome and planning therapy. Ann Surg Oncol 2003;10:713-5.
7 Interdisziplinäre Leitlinie der Deutschen Krebsgesellschaft und der beteiligten medizinischen Fachgesellschaften: Diagnostik, Therapie und Nachsorge des Mammakarzinoms - eine nationale S3 Leitlinie. www.krebsgesellschaft.de/ Leitlinien Mammakarzinom.

8 The Association of Directors of Anatomic and Surgical Pathology: ADASP Checklists for Surgical Pathology Reports of Malignant Neoplasms. www.adasp.org.

9 Tavassoli, F, Devilee P (eds): WHO Classification of Tumors - Pathology and Genetics of Tumours of Breast and Female Genital Organs. Lyon, IARC Press, 2003.

10 Sinn HP, Schmid H, Junkermann H, Huober J, Leppien G, Kaufmann M, Bastert G, Otto HF: Histologische Regression des Mammakarzinoms nach primärer (neoadjuvanter) Chemotherapie. Geburtshilfe Frauenheilkd 1994;54:552-8.

11 Fisher B, Bryant J, Wolmark N, Mamounas E, Brown A, Fisher ER, Wickerham DL, Begovic M, DeCillis A, Robidoux A, Margolese RG, Cruz AB Jr, Hoehn JL, Lees AW, Dimitrov NV, Bear HD: Effect of preoperative chemotherapy on the outcome of women with operable breast cancer. J Clin Oncol 1998;16:2672-85.

12 Wittekind Ch, Meyer HJ, Bootz F: TNM Klassifikation maligner Tumoren, 6. Auflage. Berlin, Springer, 2003.

13 Elston CW, Ellis IO: Pathological prognostic factors in breast cancer. I. The value of histological grade in breast cancer: experience from a large study with long-term follow-up. Histopathology 1991;19:403-410.

14 Remmele W, Stegner HE: Recommendation for uniform definition of an immunoreactive score (IRS) for immunohistochemical estrogen receptor detection (ER-ICA) in breast cancer tissue. Pathologe 1987;8:138-40.
15 Buzdar AU, Ibrahim NK, Francis D, Booser DJ, Thomas ES, Theriault RL, Pusztai L, Green MC, Arun BK, Giordano SH, Cristofanilli M, Frye DK, Smith TL, Hunt KK, Singletary SE, Sahin AA, Ewer MS, Buchholz TA, Berry D, Hortobagyi GN: Significantly higher pathologic complete remission rate after neoadjuvant therapy with trastuzumab, paclitaxel, and epirubicin chemotherapy: results of a randomized trial in human epidermal growth factor receptor 2-positive operable breast cancer. J Clin Oncol 2005;23:3676-85.

16 Kurosumi M, Akiyama F, Iwase T, Motomura K, Okazaki M, Tsuda H, Commitee for Production of Histopathological Criteria, Japanese Breast Cancer Society: Histopathological criteria for assessment of therapeutic response in breast cancer. Breast Cancer 2001;8:1-2.

17 Ogston KN, Miller ID, Payne S, Hutcheon AW, Sarkar TK, Smith I, Schofield A, Heys SD: A new histological grading system to assess response of breast cancers to primary chemotherapy: prognostic significance and survival. Breast 2003;12:320-7.

18 Länger F, Lück H-J, Kreipe HH: Therapieinduzierte Tumorregression beim Mammakarzinom. Pathologe 2004;25:455-460.

19 Länger F, Lück H-J, Kreipe HH: Therapieinduzierte Tumorregression beim Mammakarzinom. Pathologe 2004;25:455-460.

20 Sinn HP, Magener A, Durr F, Harcos A, von Minckwitz G: Predictive and prognostic factors in breast cancer evaluated by immunohistological methods Verh Dtsch Ges Pathol 2001;85:200-5.

21 Amat S, Penault-Llorca F, Cure H, Le Bouedec G, Achard JL, van Praagh I, Feillel V, Mouret-Reynier MA, Dauplat J, Chollet P: Scarff-Bloom-Richardson (SBR) grading: a pleiotropic marker of chemosensitivity in invasive ductal breast carcinomas treated by neoadjuvant chemotherapy. Int J Oncol 2002;20:791-6. 